\title{
A simulation model to evaluate the economic consequences of insemination programs in dairy herds: timed artificial insemination and sex-sorted semen
}

\section{Oscar Alejandro Ojeda-Rojas ${ }^{1}$ (D), Angela Maria Gonella-Diaza² (iD), Manoel Francisco de Sá Filho $^{2}$ iD, Rubens Nunes ${ }^{3}$ iD, Augusto Hauber Gameiro ${ }^{*}$}

\footnotetext{
${ }^{1}$ Universidade de São Paulo, Faculdade de Zootecnia e Engenharia de Alimentos, Programa de Pós-graduação em Gestão e Inovação na Indústria Animal, Pirassununga, SP, Brasil.

${ }^{2}$ Universidade de São Paulo, Faculdade de Medicina Veterinária e Zootecnia, Departamento de Reprodução Animal, Pirassununga, SP, Brasil.

${ }^{3}$ Universidade de São Paulo, Faculdade de Zootecnia e Engenharia de Alimentos, Departamento de Engenharia de Biossistemas, Pirassununga, SP, Brasil.

${ }^{4}$ Universidade de São Paulo, Faculdade de Medicina Veterinária e Zootecnia, Departamento de Nutrição e Produção Animal, Pirassununga, SP, Brasil.
}

\begin{abstract}
The objective of this study was to develop a simulation model to analyse the technical, economic, and financial performance of using different reproductive strategies in dairy herds. Strategies simulated were: artificial insemination (AI) using conventional semen after oestrus detection (AIC), AI using sex-sorted semen after oestrus detection (AIS), timed artificial insemination (TAI) using conventional semen (TAIC), and TAI using sex-sorted semen (TAIS). The total time horizon analysed corresponded to 25 years, divided into 425 periods of 21 days. The model simulates the biological cycle that takes place within the bovine herd, and uses input information (productive parameters, investments, and reproductive program) to calculate output information (animal inventory variance, incomes, costs, and cash flow analysis). Based on the obtained cash flow, the payback period, net present value, and internal rate of return were calculated. The payback for AIC, AIS, TAIC, and TAIS occurred in 26, 27, 23, and 25 periods. The net present value and the internal rate of return per year of the investment for AIC, AIS, TAIC, and TAIS were US\$ 557773 and 59.44\%; US\$ 520469 and 54.76\%; US\$ 741800 and 70.22\%; and US\$ 662891 and $63.52 \%$, respectively. The mean culling rate over 25 years for AIC, AIS, TAIC, and TAIS was $43.30 \%, 64.89 \%, 21.12 \%$, and $36.40 \%$, respectively. The simulation clearly demonstrated the economic and technical benefits of using TAI in dairy herds. These benefits are greater when TAI is used with conventional semen, despite the large investment in technology that is required. Using this mathematical model, future studies could be conducted when the assessment of the technical and economic viability of new scenarios is required.
\end{abstract}

Key Words: herd management, internal rate of return, net present value, payback, reproduction performance

\section{Introduction}

The economic performance of dairy herds is closely related to their reproductive efficiency, as it modulates important productive parameters, some of which directly related to main sources of income, such as milk production, quantity of animals for replacement and sales, and the genetic progress of characteristics of economic interest (Britt, 1985; Meadows et al., 2005; De Vries, 2006; Cabrera, 2014).

Parameters such as oestrus detection rate play a decisive role in artificial insemination (AI) programs

Received: December 29, 2017

Accepted: May 5, 2018

*Corresponding author: gameiro@usp.br

Copyright (C) 2018 Sociedade Brasileira de Zootecnia. This is an Open Access article distributed under the terms of the Creative Commons Attribution License (http://creativecommons.org/licenses/by/4.0/), which permits unrestricted use, distribution, and reproduction in any medium, provided the original work is properly cited.
(Galvão et al., 2013). Failures in these parameters consequently lead to increases in calving interval, which negatively affect the sources of revenue and thus compromise the profitability of the herd (Meadows et al., 2005; Giordano et al., 2012). Multiple studies have been performed to develop strategies that allow the use of AI without oestrus detection through hormonal manipulation, commonly called timed artificial insemination (TAI) (Bó et al., 2013). Despite the implementation of these techniques, not all inseminated cows became pregnant (Wiltbank et al., 2006). An important factor that affects conception rates is the type of semen used. When sexsorted semen is used, the conception rate is lower than that obtained with conventional semen (Chebel et al., 2010).

To analyse and evaluate the effects of reproductive strategies on the economic performance of the herd is not a straightforward task. In the best-case scenario, the economic return from investment in reproductive biotechnologies 
will come several months after their use and will be based on diverse sources (Britt, 1985). Simulation models are useful for this type of analysis, because they allow changes to be made in variables and parameters. Evaluating the results of these simulations permits the detection of problems and the creation of new strategies (Lovatto and Sauvant, 2001). The present study aimed to develop a mathematical simulation model that represents the causeeffect relationships between parameters and variables and, thus, analyse the consequences of using different reproductive management strategies and sex-sorted semen on the performance of a dairy herd in the state of São Paulo, Brazil from a technical, economic, and financial point of view. To achieve this objective, we created a mathematical model using a spreadsheet in Microsoft ${ }^{\circledR}$ Office Excel $^{\circledR}$, which allowed us to perform an economic analysis using the payback period, net present value, and internal rate of return as decision-making economic indicators.

\section{Material and Methods}

A mathematical model was processed using spreadsheet in Microsoft ${ }^{\circledR}$ Office Excel $^{\circledR}$ (Version 2010). Although specific simulation software programs are available, they are not necessarily user-friendly for nonscientific users such as technicians and farm managers. Also, Microsoft ${ }^{\circledR}$ Office Excel $^{\circledR}$ was chosen because it is widely available and the proposed model can thus be freely available for use in commercial farms. A deterministic model was created to simulate the dynamics of a dairy herd starting with 140 pregnant heifers and with the capacity to maintain approximately 100 lactating cows. Four scenarios of reproductive management were simulated: AI using conventional semen after oestrus detection (AIC); AI using sex-sorted semen after oestrus detection (AIS); TAI using conventional semen (TAIC); and TAI using sexsorted semen (TAIS). However, the model could be altered to simulate new scenarios with different combinations of reproductive biotechnologies in the different animal categories, according to the needs of the user. The mathematical model was carried out in Pirassununga, São Paulo State, Brazil.

We analysed the dynamics of a dairy herd using 21-day periods to represent the reproductive cycle of the average cow. The total time horizon corresponded to 25 years divided into 425 periods. In the model, one year has 357 days, corresponding to 17 periods. The model attempts to mimic the actual operations and processes that occur in a dairy herd.
The model respects the biological cycle that takes place within the bovine herd and uses input information (productive parameters, investments, and reproductive program) to calculate output information (animal inventory variance, incomes, costs, and cash flow analysis). In this way, it was possible to compare all scenarios and determine which one produced the highest profit. In the next section, we describe the biological cycle, input, and output information.

In the model, the animals were allocated to different categories: lactating cow, pregnant lactating cow, dry cow, dry cow before birth, cull cow, male calf, female calf, heifer, pregnant heifer, pregnant heifer before birth, young female, and female fattening. The biological cycle taken into account for the mathematical model (Figure 1) begins after the birth of male and female calves. At this point, all male calves are sold. Female calves remain in this category for three periods, before moving into the young female category, in which they remain for 14 periods. At the end of these two categories, the females are almost one year old (17 periods) and move to the heifer category, at which point they enter the reproductive program. The model assumes that each heifer has five opportunities (AI) to become pregnant. After five unsuccessful attempts, a heifer becomes part of the culling process and passes into the female fattening category. If a heifer successfully becomes pregnant, regardless of when it achieved gestation (first, second, third, fourth, or fifth $\mathrm{AI}$ ), it moves to the pregnant heifer category. It stays in this category for 14 periods until parturition. After parturition, the female enters the lactating cow category, in which it initially stays for three periods, considered as the voluntary waiting period. If after the voluntary waiting period and the reproductive program (seven AI attempts) the lactating cow becomes pregnant, it moves to the pregnant lactating cow category. The pregnant lactating cow category has 25 subcategories, from pregnant lactating cow 4 up to pregnant lactating cow 28. The numbers represent lactation periods. Cows that are in the pregnant lactating cow 4 subcategory gave birth four periods before and got pregnant in the first AI. As the periods pass, the females move into the next subcategory. For instance, a female that is in subcategory pregnant lactating cow 4 in period 38 will become a pregnant lactating cow 5 in period 39. This continues until 11 periods are completed (gestation during the lactation period). After that, the female passes into the dry cow category. In this category, the female waits for three periods before a new parturition and subsequently passes into the lactating cow category, thus starting the cycle again. However, if after the reproductive program the female lactating cow does not 
become pregnant, it becomes part of the animals for culling, the female fattening category. In the case of the voluntary culling of cows (due to low production, conformation traits, etc.), immediately after parturition the cows are classified as cull cows. This category has the same flow scheme as the lactating cow category, but in the cull cow category, cows are not exposed to the reproductive program, and, after lactation (19 periods), they are culled.

The inputs consist of the information that the model uses to make calculations. They were organised into the following categories: productive parameters, reproductive parameters and reproductive program, prices of supplies and equipment, investments, labour, and annual average costs per animal.

The productive parameters considered in the model are explained in the next section. The mortality rate varies according to the animal category. In young animals $(<1$ year), it was $6.50 \%$ (Giordano et al., 2012), regardless of sex. In adult animals, the mortality rate was $1.00 \%$ in non-lactating cows (Overton, 2005); and in lactating cows, the mortality rate was $6.60 \%$ (Pinedo et al., 2010). The number of pregnant heifers for sale and the voluntary culling were determined according to each scenario, since those parameters derive from the number of available animals and the capacity of the farm to maintain them. As previously mentioned, the model considers subcategories within the lactating cow category according to the lactation period. This allows individual milk production data to be calculated using the lactation curve model proposed by Congleton and Everett (1980). The total milk production in each period was then calculated by multiplying the number of cows in each subcategory by its respective milk production. The maximum duration of the lactation period was 28 periods, corresponding to 588 days.

Pregnancy loss, oestrus detection rate, and conception rate values considered in the simulation of the four scenarios correspond mostly to North American references, because unfortunately, most Brazilian studies consider low numbers of animals and extremely heterogeneous production systems in terms of genetics, nutrition, and management (Table 1). However, the model allows the user to change the values of the reproductive parameters to be more similar to their individual situation.

The reproductive program in the herd varies according to the scenarios evaluated. The inter-service interval was one period ( 21 days) for AI scenarios and two periods (42

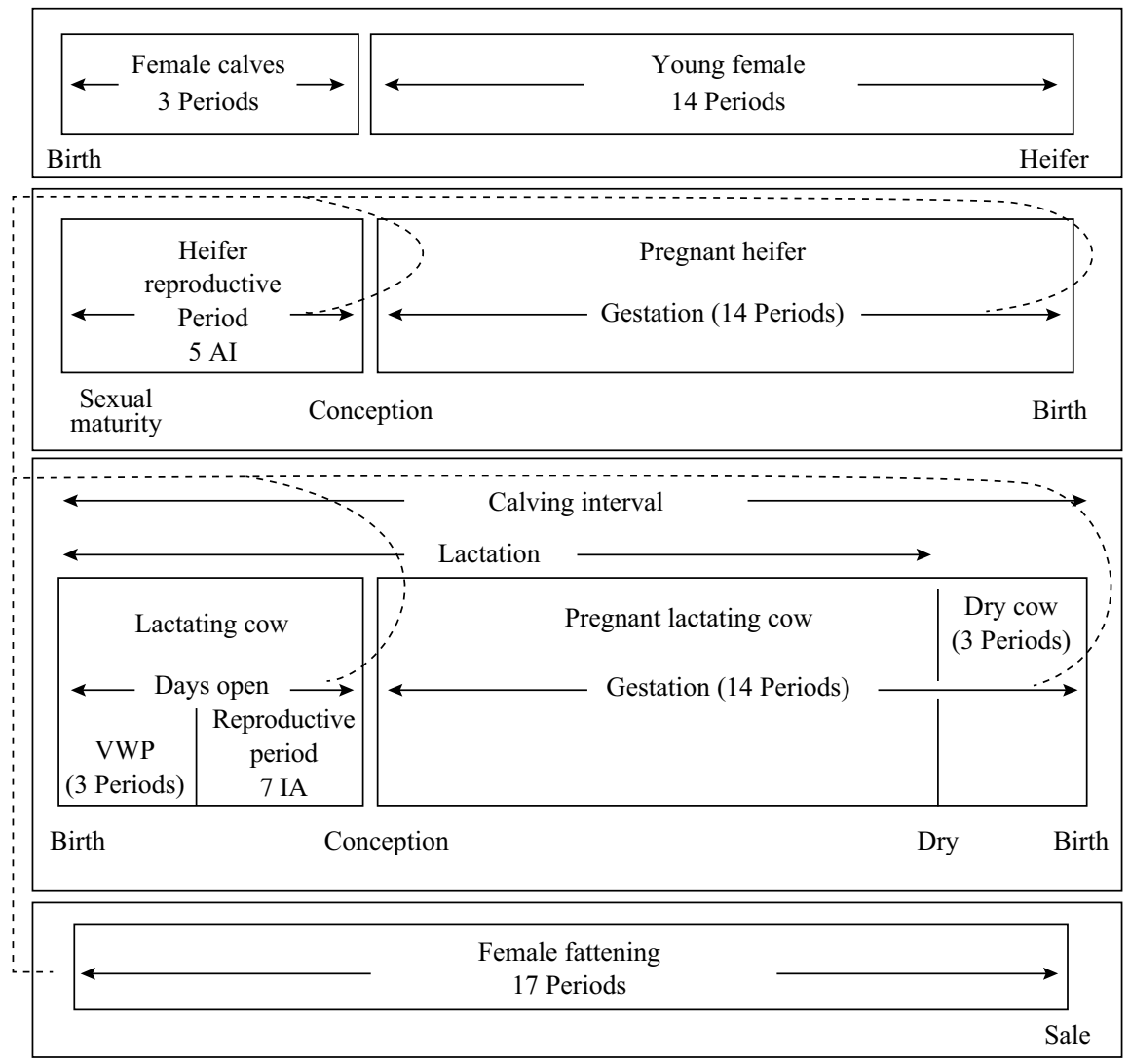

VWP - voluntary waiting period; AI - artificial insemination.

Figure 1 - Dairy production cycle considered in the mathematical model. 
Table 1 - Values of the reproductive parameters considered in the model for heifers and cows

\begin{tabular}{lccccc}
\hline \multirow{2}{*}{ Parameter } & \multicolumn{2}{c}{ Heifer } & & \multicolumn{2}{c}{ Cow } \\
\cline { 2 - 3 } \cline { 5 - 6 } & Value & Source & Value & Source \\
\hline Pregnancy loss $<90$ days & $8.00 \%$ & (Seidel and Schenk, 2008) & $9.60 \%$ & $($ Galvão et al., 2013) \\
Pregnancy loss $>90$ days & $1.70 \%$ & (Galvão et al., 2013) & $1.70 \%$ & $($ Galvão et al., 2013) \\
Ostrus detection rate (AI) & $65.00 \%$ & (Giordano et al., 2012) & $40.00 \%$ & $($ De Vries, 2006) & (De Vries, 2006) \\
Ostrus detection rate (TAI) & $100.00 \%$ & (Giordano et al., 2012) & 100.00 & $31.50 \%$ & (DeJarnette et al., 2008) \\
Conception rate (conventional semen) & $56.30 \%$ & (Kuhn et al., 2006) & 23.00\% & (DeJarnette et al., 2008) \\
Conception rate (sex-sorted semen) & $39.00 \%$ & (Norman et al., 2010) & &
\end{tabular}

$\mathrm{AI}$ - artificial insemination; TAI - timed artificial insemination.

days) for TAI scenarios, whether for heifers or cows. The proportions of female and male calves born after using sexsorted semen were 85.70 and $14.30 \%$, respectively (Chebel et al., 2010). The proportions of the use of conventional semen were $46.70 \%$ females and $53.30 \%$ males (Silva Del Río et al., 2007). In the scenarios including TAI, the use of a protocol based on progesterone and estradiol was simulated (Pereira et al., 2013). The simulated reproductive protocol consisted of the insertion of a progesterone device and an intramuscular injection of $2.0 \mathrm{mg}$ estradiol benzoate at day 0 . After seven days, there was an intramuscular injection of $25 \mathrm{mg}$ of PGF $2 \alpha ; 24 \mathrm{~h}$ later, the device was removed, and $1.00 \mathrm{mg}$ estradiol cypionate was injected. Timed artificial insemination was carried out $48 \mathrm{~h}$ after the removal of the device.

The prices of supplies and equipment were determined using a survey performed in the second half of 2016. The budgets were estimated based on information from dairy farm suppliers and dairy farmers in the state of São Paulo (Brazil). The American dollar (US\$) was considered as the monetary unit, and for that period, the average exchange rate was US\$ $1.00=\mathrm{R} \$ 3.68$ (Brazilian Reais; source: Central Bank of Brazil). Therefore, the prices considered in the model were: litre of milk, US\$ 0.24 ; price per cow of discard, US\$ 326.00 ; price of calves ( $<10$ days of age), US\$ 22.00; price of pregnant heifers, US\$ 760.00; and price of fattening females, US\$ 353.00 .

The model considered the purchase or sale of pregnant heifers (231 days of pregnancy) to maintain approximately 100 lactating cows. Thus, every time the animal inventory was reduced, pregnant heifers were purchased. In other cases, when the production of pregnant heifers increased the necessities of the herd replacements, the surplus were sold, and this made part of the income of the herd. In both cases, purchasing or selling pregnant heifers, the price considered was US\$760.00.

The animals, facilities, and equipment were considered as initial investments in period zero of the cash flow (US\$ 169,021.73). These initial investments were the same for all four scenarios evaluated. The requirement for workers was calculated according to the milk production. The productivity per employee was estimated in units of $500 \mathrm{~L}$ of milk/man/day.

Finally, regardless of the reproductive scenario evaluated, the length of the gestation was 14 periods for both cows and heifers. When pregnancy losses occurred with less than 90 days of gestation, females were returned to the reproductive program. When the pregnancy losses occurred after more than 90 days of gestation, females were withdrawn from the herd and moved into the female fattening category.

For each animal category, average annual costs were calculated for feed, health management programs, animal handling, and reproductive programs (Table 2). To obtain the costs per period (21 days), the annual cost was divided by 17 . To calculate the cost of animal maintenance in a determined period, for example of lactating cows for period 1, the number of lactating cows was multiplied by $1 / 17$ of the annual cost for lactating cows. To calculate the cost of the reproductive program, the prices of equipment, hormones, and supplies were taken into account (Table 3 ). In all cases, the parameters used were the means of the expected values.

The outputs of the model are the information generated by the model based on the input data provided, namely:

Table 2 - Annual costs (US\$) by animal category in dairy herd ${ }^{1}$

\begin{tabular}{lcccc}
\hline Category & Feeding & $\begin{array}{c}\text { Health and } \\
\text { management }\end{array}$ & Reproduction & Total \\
\hline Lactating cow & 883.00 & 11.47 & 2.45 & 896.92 \\
Male calf & 14.67 & 0.24 & - & 14.91 \\
Female calf & 132.23 & 6.71 & - & 138.94 \\
Heifer & 212.12 & 2.23 & 2.45 & 216.8 \\
Dry cow & 73.86 & 1.25 & 0.82 & 75.93 \\
Pregnant heifer & 73.86 & 2.66 & 0.82 & 77.34 \\
Young female & 141.96 & 1.96 & - & 143.92 \\
Female fattening & 93.48 & 1.52 & 0.82 & 95.82 \\
\hline
\end{tabular}

${ }^{1}$ These values were obtained using personal visits and calls to producers and distributors of agricultural products. The mean values of the various sources were used, and outliers were eliminated. 
animal inventory variance, income, costs per category, and cash flow. Based on the interactions between the mathematical equations and the mentioned parameters, animal inventory variation is generated for each period. Within each period, the model was structured using multiple mathematical equations (Table 4). This structure allows categories of animals and parameters, some of them concerning specific scenarios, to interact with each other to determine the allocation of animals and the total animal inventory by period and by category. Each period has an initial number of animals, a flow within categories (entries and exits between the different categories during the 21 days of each period), and a final allocation of animals at the end of the period. In all cases, the final number of animals at the end of a period will be the initial number at the beginning of the next, and the cycle can be repeated once again.

Only the sales of milk and animals (male calf, cull cow, pregnant heifer, and female fattening categories) were considered as income. The cost per category was calculated by multiplying the number of animals per category by the average cost of each category. Additionally, reproductive costs were attributed to the number of animals entering the reproductive program, although the number varied depending on the strategy adopted.

Table 3 - Values ${ }^{1}$ (US\$) of the AI equipment, inputs, and protocol used in the reproductive program of dairy herd considered in the model

\begin{tabular}{lc}
\hline Item & Price \\
\hline Equipment and supplies & \\
Liquid nitrogen tank 20/20 & 559.00 \\
Carry case & 11.17 \\
Insemination gun & 27.66 \\
Straw tweezers & 8.23 \\
Straw cutter & 9.42 \\
Thermometer & 12.36 \\
Digital semen thaw unit & 271.74 \\
Liquid nitrogen measuring stick & 1.77 \\
Nitrogen refill/year & 51.00 \\
Disposable rectal examination gloves & 8.84 \\
Insemination sheaths & 5.00 \\
Straw of conventional semen & 8.15 \\
Straw of sex-sorted semen & 24.45 \\
Others & 29.43 \\
TAI protocol & \\
Intravaginal progesterone devices & 2.72 \\
Dose of estradiol benzoate & 0.33 \\
Dose of eCG & 2.17 \\
Dose of prostaglandin F2alpha & 0.54 \\
\hline AI - artificial insemination; TAI - timed artificial insemination; & eCG - equine \\
distributors of agricultural products. The mean values of the various sources were \\
used and the outliers were eliminated. & \\
\hline & \\
\hline &
\end{tabular}

Once the information on inputs and outputs was available, it was organised and analysed objectively. For better understanding of the organisation, cash flow was summarised in annual periods over 25 years. The information from year 1 (starting in period 1) and up to year 25 (ending in period 425) was taken into account in the cash flow analysis.

In the first period, the total value of the animal inventory, facilities, and equipment were considered as investments (costs in year 0). Finally, the discount rate used was $12 \%$ per year for all scenarios; the choice of this discount rate was arbitrary, but in accordance with the Brazilian macroeconomic reality.

Based on the obtained cash flow, the payback period, net present value, and internal rate of return were calculated by economic analysis methods. The internal rate of return is an indicator that not only allows comparisons between different simulated scenarios, but also allows simple comparisons with alternative activities such as financial investments. All of the presented results are the product of simulated herds with the capacity (including facilities and soil) to maintain approximately 100 lactating cows. As previously mentioned, when a simulated scenario showed an inability to maintain the animal inventory, the model considered the purchase of pregnant heifers. The results are based on the simulation of the productive unit (the herd), with emphasis on the population dynamics and not on the individual.

Finally, using the AIC scenario, a sensitivity analysis was performed to determine the effect of increasing the oestrus detection rate in cows in steps of five percentage points, from 40.0 to $90.0 \%$, ceteris paribus (maintaining the values of all other parameters constant). The effects on the average culling rate, average number of females inseminated per year, average total milk production of the herd per day, net present value, and internal rate of return were considered.

\section{Results}

Based on cash flows, the economic viability of the four scenarios (AIC, AIS, TAIC, and TAIS) was calculated (Table 5). The payback for the AIC scenario occurred in period 26, the net present value of the investment was US\$ 557773 , and the result of the calculation of the internal rate of return was $59.44 \%$ per year. For the AIS scenario, the payback occurred in period 27 , the net present value was of US\$ 520469, and the internal rate of return $54.76 \%$ per year. The payback of the TAIC scenario took place in period 23 and the net present value and internal rate 
Table 4 - Mathematical equations of the simulation model to evaluate the economic consequences of insemination programs in dairy herds

$P H 1_{0}=140 \forall \mathrm{t}=0$

in which $P H 1_{0}=$ pregnant heifers in the period $\mathrm{t}=0$.

$L C_{t}=D C B_{t}+P H P_{t} \forall \mathrm{t}$

in which $L C_{t}=$ lactating cows in the period $\mathrm{t} ; D C B_{t}=$ dry cow before birth in the period $\mathrm{t}$; and $P H P_{t}=$ pregnant heifer before birth in the period $\mathrm{t}$.

$L C 1_{t}=L C_{t}(1-\epsilon)\left(1-\omega_{t}\right) \forall \mathrm{t}$

in which $L C 1_{t}=$ lactating cows available for first $\mathrm{AI}$ in the period $\mathrm{t} ; L C_{t}=$ lactating cow in the period $\mathrm{t} ; \epsilon=\%$ mortality rate in adult animals; and $\omega_{t}=\%$ culling rate in cows per year, equal to zero for $\mathrm{t}<50\left(\omega_{t}=0 \mathrm{FOR} \mathrm{t}=[1,2,3,4 \ldots 49]\right)$.

$L C 2_{t}=\left(\left(\left(L C 1_{t-1}(1-\theta \Lambda)\right)+\left(\left(\left(L C 1_{t-1} \theta \Lambda\right)(1-\Pi)\right) \beta\right)\right)(1-\Pi)\right) \forall \mathrm{t}$

in which $L C 2_{t}=$ lactating cows available for second AI in the period $\mathrm{t} ; V L D 1_{t-1}=$ lactating cows available for first AI in the period $\mathrm{t}-1 ; \theta=\%$ oestrus detection rate in cows in the first $\mathrm{AI} ; \Lambda=\%$ conception rate in cows in the first $\mathrm{AI} ; \beta=\%$ pregnancy loss in cows $<90$ days; and $\Pi=\%$ mortality rate in lactating cows.

$L C 3_{t}=\left(\left(\left(L C 2_{t-1}(1-\imath \mathrm{K})\right)+\left(\left(\left(L C 2_{t-1} t \mathrm{~K}\right)(1-\Pi)\right) \beta\right)\right)(1-\Pi)\right) \forall \mathrm{t}$

in which $L C 3_{t}=$ lactating cows available for third $\mathrm{AI}$ in the period $\mathrm{t} ; L C 2_{t-1}=$ lactating cows available for second $\mathrm{AI}$ in the period $\mathrm{t}-1 ; l=\%$ oestrus detection rate in cows in the second $\mathrm{AI} ; \mathrm{K}=\%$ conception rate in cows in the second $\mathrm{AI} ; \beta=\%$ pregnancy loss in cows $<90$ days; and $\Pi=\%$ mortality rate in lactating cows.

$L C 4_{t}=\left(\left(\left(L C 3_{t-1}(1-\lambda \mu)\right)+\left(\left(\left(L C 3_{t-1} \lambda \mu\right)(1-\Pi)\right) \beta\right)\right)(1-\Pi)\right) \forall \mathrm{t}$

in which $L C 4_{t}=$ lactating cows available for fourth $\mathrm{AI}$ in the period $\mathrm{t} ; L C 3_{t-1}=$ lactating cows available for third $\mathrm{AI}$ in the period $\mathrm{t}-1 ; \lambda=\%$ oestrus detection rate in cows in the third $\mathrm{AI} ; \mu=\%$ conception rate in cows in the third $\mathrm{AI} ; \beta=\%$ pregnancy loss in cows $<90$ days; and $\Pi=\%$ mortality rate in lactating cows.

$L C 5_{t}=\left(\left(\left(L C 4_{t-1}(1-\mathrm{EZ})\right)+\left(\left(\left(L C 4_{t-1} \mathrm{EZ}\right)(1-\Pi)\right) \beta\right)\right)(1-\Pi)\right) \forall \mathrm{t}$

in which $L C 5_{t}=$ lactating cows available for fifth $\mathrm{AI}$ in the period $\mathrm{t} ; L C 4_{t-1}=$ lactating cows available for fourth $\mathrm{AI}$ in the period $\mathrm{t}-1 ; \mathrm{E}=\%$ oestrus detection rate in cows in the fourth $\mathrm{AI} ; \mathrm{Z}=\%$ conception rate in cows in the fourth $\mathrm{AI} ; \beta=\%$ pregnancy loss in cows $<90$ days; and $\Pi=\%$ mortality rate in lactating cows.

$L C 6_{t}=\left(\left(\left(L C 5_{t-1}(1-\Psi \Omega)\right)+\left(\left(\left(L C 5_{t-1} \Psi \Omega\right)(1-\Pi)\right) \beta\right)\right)(1-\Pi)\right) \forall \mathrm{t}$

in which $L C 6_{t}=$ lactating cows available for sixth AI in the period $\mathrm{t} ; L C 5_{t-1}=$ lactating cows available for fifth AI in the period $\mathrm{t}-1 ; \Psi=\%$ oestrus detection rate in cows in the fifth $\mathrm{AI} ; \Omega=\%$ conception rate in cows in the fifth $\mathrm{AI} ; \beta=\%$ pregnancy loss in cows $<90$ days; and $\Pi=\%$ mortality rate in lactating cows.

$L C 7_{t}=\left(\left(\left(L C 6_{t-1}(1-\mathrm{TO})\right)+\left(\left(\left(L C 6_{t-1} \mathrm{TO}\right)(1-\Pi)\right) \beta\right)\right)(1-\Pi)\right) \forall \mathrm{t}$

in which $L C 7_{t}=$ lactating cows available for seventh $\mathrm{AI}$ in the period $\mathrm{t} ; L C 6_{t-1}=$ lactating cows available for sixth $\mathrm{AI}$ in the period $\mathrm{t}-1 ; \mathrm{T}=\%$ oestrus detection rate in cows in the sixth $\mathrm{AI} ; \mathrm{O}=\%$ conception rate in cows in the sixth $\mathrm{AI} ; \beta=\%$ pregnancy loss in cows $<90$ days; and $\Pi=\%$ mortality rate in lactating cows.

$P L C 1_{t}=\left(L C 1_{t} \theta \Lambda(1-\Pi)\right)(1-\beta) \forall \mathrm{t}$

in which $P L C 1_{t}=$ pregnant lactating cow after first AI in the period $\mathrm{t} ; L C 1_{t}=$ lactating cows available for first AI in the period $\mathrm{t} ; \theta=\%$ oestrus detection rate in cows in the first $\mathrm{AI} ; \Lambda=\%$ conception rate in cows in the first $\mathrm{AI} ; \beta=\%$ pregnancy loss in cows $<90$ days; and $\Pi=\%$ mortality rate in lactating cows.

$P L C 2_{t}=\left(L C 2_{t} \imath \mathrm{K}(1-\Pi)\right)(1-\beta) \forall \mathrm{t}$

in which $P L C 2_{t}=$ pregnant lactating cow after second $\mathrm{AI}$ in the period $\mathrm{t} ; L C 2_{t}=$ lactating cows available for second $\mathrm{AI}$ in the period $\mathrm{t} ; l=\%$ oestrus detection rate in cows in the second $\mathrm{AI} ; \mathrm{K}=\%$ conception rate in cows in the second $\mathrm{AI} ; \beta=\%$ pregnancy loss in cows $<90$ days; and $\Pi=\%$ mortality rate in lactating cows.

$P L C 3_{t}=\left(L C 3_{t} \lambda \pi(1-\Pi)\right)(1-\beta) \forall \mathrm{t}$

in which $P L C 3_{t}=$ pregnant lactating cow after third AI in the period $\mathrm{t} ; L C 3_{t}=$ lactating cows available for third $\mathrm{AI}$ in the period $\mathrm{t} ; \lambda=\%$ oestrus detection rate in cows in the third AI; $\pi=\%$ conception rate in cows in the third $\mathrm{AI} ; \beta=\%$ pregnancy loss in cows $<90$ days; and $\Pi=\%$ mortality rate in lactating cows.

$P L C 4_{t}=\left(L C 4_{t} \mathrm{EZ}(1-\Pi)\right)(1-\beta) \forall \mathrm{t}$

in which $P L C 4_{t}=$ pregnant lactating cow after fourth $\mathrm{AI}$ in the period $\mathrm{t} ; L C 4_{t}=$ lactating cows available for fourth $\mathrm{AI}$ in the period $\mathrm{t}$; $\mathrm{E}=\%$ oestrus detection rate in cows in the fourth $\mathrm{AI} ; \mathrm{Z}=\%$ conception rate in cows in the fourth $\mathrm{AI} ; \beta=\%$ pregnancy loss in cows $<90$ days; and $\Pi=\%$ mortality rate in lactating cows.

$P L C 5_{t}=\left(L C 5_{t} \Psi \Omega(1-\Pi)\right)(1-\beta) \forall \mathrm{t}$

in which $P L C 5_{t}=$ pregnant lactating cow after fifth $\mathrm{AI}$ in the period $\mathrm{t} ; L C 5_{t}=$ lactating cows available for fifth $\mathrm{AI}$ in the period $\mathrm{t}$; $\Psi=\%$ oestrus detection rate in cows in the fifth AI; $\Omega=\%$ conception rate in cows in the fifth AI; $\beta=\%$ pregnancy loss in cows $<90$ days; and $\Pi=\%$ mortality rate in lactating cows.

$P L C 6_{t}=\left(L C 6_{t}\right.$ TO $\left.(1-\Pi)\right)(1-\beta) \forall \mathrm{t}$

in which $P L C 6_{t}=$ pregnant lactating cow after sixth AI in the period $\mathrm{t} ; L C 6_{t}=$ lactating cows available for sixth $\mathrm{AI}$ in the period $\mathrm{t}$; $\mathrm{T}=\%$ oestrus detection rate in cows in the sixth $\mathrm{AI} ; \mathrm{O}=\%$ conception rate in cows in the sixth $\mathrm{AI} ; \beta=\%$ pregnancy loss in cows $<90$ days; and $\Pi=\%$ mortality rate in lactating cows.

$P L C 7_{t}=\left(L C 7_{t} \mathrm{HI}(1-\Pi)\right)(1-\beta) \forall \mathrm{t}$

in which $P L C 7_{t}=$ pregnant lactating cow after seventh $\mathrm{AI}$ in the period $\mathrm{t} ; L C 7_{t}=$ lactating cows available for seventh $\mathrm{AI}$ in the period $\mathrm{t} ; \mathrm{H}=\%$ oestrus detection rate in cows in the seventh $\mathrm{AI} ; \mathrm{I}=\%$ conception rate in cows in the seventh $\mathrm{AI} ; \beta=\%$ pregnancy loss in cows $<90$ days; and $\Pi=\%$ mortality rate in lactating cows. 
Table 4 (Continued)

Equation

$\left.D C=\left(\left(\left(P L C 1_{t-I I}+P L C 2_{t-l l}+P L C 3_{t-l l}+P L C 4_{t-l l}+P L C 5_{t-l l}+P L C 6_{t-l l}+P L C 7_{t-1 I}\right)(1-\Pi)^{11}\right)(1-\epsilon)\right)(1-\mathrm{B})\right) \forall \mathrm{t}$

in which $D C=$ dry cow in the period $\mathrm{t} ; P L C 1_{t}=$ pregnant lactating cow after first AI in the period $\mathrm{t}-11 ; P L C 2_{t}=$ pregnant lactating cow after second $\mathrm{AI}$ in the period $\mathrm{t}-11 ; P L C 3$ = pregnant lactating cow after third $\mathrm{AI}$ in the period $\mathrm{t}-11 ; P L C 4$ = pregnant lactating cow after fourth $\mathrm{AI}$ in the period $\mathrm{t}-11 ; P L C 5_{t}=$ pregnant lactating cow after fifth AI in the period $\mathrm{t}-11 ; P L C 6_{t}=$ pregnant lactating cow after sixth AI in the period $\mathrm{t}-11$; $P L C 7_{t}=$ pregnant lactating cow after seventh $\mathrm{AI}$ in the period $\mathrm{t}-11 ; \Pi=\%$ mortality rate in lactating cows; $\epsilon=\%$ mortality rate in adult animals; and $\beta=\%$ pregnancy loss in cows $<90$ days.

$D C B_{t}=D C_{t-3}(1-\epsilon)^{3} \forall \mathrm{t}$

in which $D C B_{t}=$ dry cow before birth in the period t; $D C=$ dry cow in the period $\mathrm{t}$; and $\epsilon=\%$ mortality rate in adult animals.

$Y F_{t}=F C_{t-3}(1-\delta)^{4} \forall \mathrm{t}$

in which $Y F_{t}=$ young female (3-12 months); $F C_{t-3}=$ cow-calf ( $<3$ months) birth in the period $\mathrm{t}-3$; and $\delta=\%$ mortality rate in cow-calf $(<1$ year).

$H_{t}=F C_{t-17}(1-\delta)^{18} \forall \mathrm{t}$

in which $H_{t}=$ heifer in the period $\mathrm{t} ; F C_{t-17}=$ cow-calf ( $<3$ months) birth in the period $\mathrm{t}-17$; and $\delta=\%$ mortality rate in cow-calf $(<1$ year $)$.

$P P H_{t}=$ User-defined $\forall \mathrm{t}>14$

in which $P P H_{t}=$ purchased pregnant heifers, equal to zero for $\mathrm{t}<15$ (Tat $=0$ for $\left.\mathrm{t}=[1,2,3 \ldots 14]\right)$.

$H 1_{t}=H_{t}(1-\epsilon) \forall \mathrm{t}$

in which $H 1_{t}=$ heifers available for first $\mathrm{AI}$ in the period $\mathrm{t} ; H_{t}=$ heifer in the period $\mathrm{t}$; and $\epsilon=\%$ mortality rate in adult animals.

$H 2_{t}=\left(\left(\left(H 1_{t-1}(1-\kappa \rho)\right)+\left(\left(H 1_{t-1} \kappa \rho(1-\epsilon)\right) \alpha\right)\right)(1-\epsilon)\right)(1-\epsilon) \forall \mathrm{t}$

in which $H 2_{t}=$ heifers available for second $\mathrm{AI}$ in the period $\mathrm{t} ; H 1_{t-1}=$ heifers available for first $\mathrm{AI}$ in the period $\mathrm{t}-1 ; \kappa=\%$ oestrus detection rate in heifers in the first $\mathrm{AI} ; \rho=\%$ conception rate in heifers in the first $\mathrm{AI} ; \epsilon=\%$ mortality rate in adult animals; and $\alpha=\%$ pregnancy loss in heifers $<90$ days.

$H 3_{t}=\left(\left(\left(H 2_{t-1}(1-\varrho \sigma)\right)+\left(\left(H 2_{t-1} \varrho \sigma(1-\epsilon)\right) \alpha\right)\right)(1-\epsilon)\right)(1-\epsilon) \forall \mathrm{t}$

in which $H 3_{t}=$ heifers available for third AI in the period $\mathrm{t} ; H 2_{t-1}=$ heifers available for second $\mathrm{AI}$ in the period $\mathrm{t}-1 ; \varrho=\%$ oestrus detection rate in heifers in the second $\mathrm{AI} \sigma=\%$ conception rate in heifers in the second $\mathrm{AI} ; \epsilon=\%$ mortality rate in adult animals; and $\alpha=\%$ pregnancy loss in heifers $<90$ days.

$H 4_{t}=\left(\left(\left(H 3_{t-1}(1-\varsigma \tau)\right)+\left(\left(H 3_{t-1} \varsigma \tau(1-\epsilon)\right) \alpha\right)\right)(1-\epsilon)\right)(1-\epsilon) \forall \mathrm{t}$

in which $H 4_{t}=$ heifers available for fourth $\mathrm{AI}$ in the period $\mathrm{t} ; H 3_{t-1}=$ heifers available for third $\mathrm{AI}$ in the period $\mathrm{t}-1 ; \varsigma=\%$ oestrus detection rate in heifers in the third AI; $\tau=\%$ conception rate in heifers in the third AI; $\epsilon=\%$ mortality rate in adult animals; and $\alpha=\%$ pregnancy loss in heifers $<90$ days.

$H 5_{t}=\left(\left(\left(H 4_{t-1}(1-\Gamma \Theta)\right)+\left(\left(H 4_{t-1} \Gamma \Theta(1-\epsilon)\right) \alpha\right)\right)(1-\epsilon)\right)(1-\epsilon) \forall \mathrm{t}$

in which $H 5_{t}=$ heifers available for fifth $\mathrm{AI}$ in the period $\mathrm{t} ; H 4_{t-1}=$ heifers available for fourth $\mathrm{AI}$ in the period $\mathrm{t}-1 ; \Gamma=\%$ oestrus detection rate in heifers in the fourth $\mathrm{AI} ; \Theta=\%$ conception rate in heifers in the fourth $\mathrm{AI} ; \epsilon=\%$ mortality rate in adult animals; and $\alpha=\%$ pregnancy loss in heifers $<90$ days.

$P H 1_{t}=\left(\left(\left(H 1_{t} \kappa \rho(1-\epsilon)\right)(1-\alpha)\right)\left(1-\Delta_{t}\right)\right)+P P H_{t} \forall \mathrm{t}$

in which $P H 1_{t}=$ pregnant heifers after first AI in the period $\mathrm{t} ; H 1_{t}=$ heifers available for first $\mathrm{AI}$ in the period $\mathrm{t} ; \kappa=\%$ oestrus detection rate in heifers in the first AI; $\rho=\%$ conception rate in heifers in the first AI; $\epsilon=\%$ mortality rate in adult animals; $\alpha=\%$ pregnancy loss in heifers $<90$ days; and $\Delta_{t}=\%$ pregnant heifers for sale, equal to zero for $\mathrm{t}<35\left(\Delta_{t}=0\right.$ for $\left.\mathrm{t}=[1,2,3 \ldots 34]\right)$.

$P P H 1_{t}=$ purchased pregnant heifers, equal to zero for $\mathrm{t}<15\left(\Delta_{-} \mathrm{t}=0\right.$ for $\left.\mathrm{t}=[1,2,3 \ldots 14]\right)$.

$P H 2_{t}=\left(\left(H 2_{t} \varrho \sigma(1-\epsilon)\right)(1-\alpha)\right)(1-\Delta) \forall \mathrm{t}$

in which $P H 2_{t}=$ pregnant heifers after second AI in the period $\mathrm{t} ; H 2=$ heifers available for second AI in the period $\mathrm{t} ; \varrho=\%$ oestrus detection rate in heifers in the second AI; $\sigma=\%$ conception rate in heifers in the second AI; $\epsilon=\%$ mortality rate in adult animals; $\alpha=\%$ pregnancy loss in heifers $<90$ days; and $\Delta_{t}=\%$ pregnant heifers for sale, equal to zero for $\mathrm{t}<35\left(\Delta_{t}=0\right.$ for $\left.\mathrm{t}=[1,2,3 \ldots 34]\right)$.

$P H 3_{t}=\left(\left(H 3_{t} \varsigma \tau(1-\epsilon)\right)(1-\alpha)\right)\left(1-\Delta_{t}\right) \forall \mathrm{t}$

in which $P H 3_{t}=$ pregnant heifers after third AI in the period $\mathrm{t} ; H 3_{t}=$ heifers available for third $\mathrm{AI}$ in the period $\mathrm{t}$; $\varsigma=\%$ oestrus detection rate in heifers in the third AI; $\tau=\%$ conception rate in heifers in the third AI; $\epsilon=\%$ mortality rate in adult animals; $\alpha=\%$ pregnancy loss in heifers $<90$ days; and $\Delta_{t}=\%$ pregnant heifers for sale, equal to zero for $\mathrm{t}<35\left(\Delta_{t}=0\right.$ for $\left.\mathrm{t}=[1,2,3 \ldots 34]\right)$.

$P H 4_{t}=\left(\left(H 4_{t} \Gamma \Theta(1-\epsilon)\right)(1-\alpha)\right)\left(1-\Delta_{t}\right) \forall \mathrm{t}$

in which $\mathrm{PH}_{t}=$ pregnant heifers after fourth AI in the period $\mathrm{t} ; 4_{t}=$ heifers available for fourth $\mathrm{AI}$ in the period $\mathrm{t} ; \Gamma=\%$ oestrus detection rate in heifers in the fourth $\mathrm{AI} ; \Theta=\%$ conception rate in heifers in the fourth AI; $\epsilon=\%$ mortality rate in adult animals; $\alpha=\%$ pregnancy loss in heifers $<90$ days; and $\Delta_{t}=\%$ pregnant heifers for sale, equal to zero for $\mathrm{t}<35\left(\Delta_{t}=0\right.$ for $\left.\mathrm{t}=[1,2,3 \ldots 34]\right)$.

$P H 5_{t}=\left(\left(H 5_{t} \mathrm{X} \Phi(1-\epsilon)\right)(1-\alpha)\right)\left(1-\Delta_{t}\right) \forall \mathrm{t}$

in which $P H 5_{t}=$ pregnant heifers after fifth AI in the period $\mathrm{t} ; H 5_{t}=$ heifers available for fifth $\mathrm{AI}$ in the period $\mathrm{t}$; $\mathrm{X}=\%$ oestrus detection rate in heifers in the fifth AI; $\Phi=\%$ conception rate in heifers in the fifth $\mathrm{AI} ; \epsilon=\%$ mortality rate in adult animals; $\alpha=\%$ pregnancy loss in heifers $<90$ days; and $\Delta_{t}=\%$ pregnant heifers for sale, equal to zero for $\mathrm{t}<35\left(\Delta_{t}=0\right.$ for $\left.\mathrm{t}=[1,2,3 \ldots 34]\right)$.

$P H B_{t}=\left(\left(P H 1_{t-14}+P H 2_{t-14}+P H 3_{t-14}+P H 4_{t-14}+P H 5_{t-14}\right)(1-\epsilon)^{14}\right)(1-\mathrm{A}) \forall \mathrm{t}$

in which $P H B_{t}^{t-14}=$ pregnant heifer before birth in the period $\mathrm{t}$; $P H 1_{t-14}=$ pregnant heifers after first AI in the period $\mathrm{t}-14 ;$; $P H 2_{t-14}=$ pregnant heifers after second $\mathrm{AI}$ in the period $\mathrm{t}-14 ; P H 3_{t-14}=$ pregnant heifers after third $\mathrm{AI}$ in the period $\mathrm{t}-14 ; P H 4_{t-14}=$ pregnant heifers after fourth AI in the period $\mathrm{t}-14 ;$ PH5 $_{t-14}=$ pregnant heifers after fifth $\mathrm{AI}$ in the period $\mathrm{t}-14 ; \epsilon=\%$ mortality rate in adult animals; and $\mathrm{A}=\%$ pregnancy loss in heifers $>90$ days.

$B C_{1}=\gamma L C_{1} \forall \mathrm{t}=1$

in which $C M_{1}=$ calves born in year $\mathrm{t}=1 ; \gamma=\%$ gestations with bull-calf/cow-calf product by natural service; and $L C_{1}=$ lactating cow in the period $\mathrm{t}=1$. 
Table 4 (Continued)

Equation

$B C_{t}=\left(\left(\left(\left(\xi P L C 1_{t-14}+o P L C 2_{t-14}+\pi P L C 3_{t-14}+\Upsilon P L C 4_{t-14}+\varphi P L C 5_{t-14}+\chi P L C 6_{t-14}+P P L C 7_{t-14}\right)(1-\Pi)^{11}\right)(1-\epsilon)\right)(1-\mathrm{B})\right)(1-\epsilon)^{3}+\left(\left(\left(\xi P H 1_{t-14}+\right.\right.\right.$ $\left.\left.\left.o P H 2_{t-14}+\pi P H 3_{t-14}+\Upsilon P H 4_{t-14}+\varphi P H 5_{t-14}\right)(1-\epsilon)^{14}\right)(1-\mathrm{A})\right) \forall \mathrm{t}>1$

in which $B C_{t}=$ bull-calf - number of calves born after the reproductive program of the farm, taking into account the semen technology used in the period $\mathrm{t}>1 ; \xi=\%$ gestations with bull-calf product in the first AI; $o=\%$ gestations with bull-calf product in the second AI; $\pi=\%$ gestations with bull-calf product in the third AI; $\Upsilon=\%$ gestations with bull-calf product in the fourth AI; $\varphi=\%$ gestations with bull-calf product in the fifth AI; $\chi=\%$ gestations with bull-calf product in the sixth AI; $\mathrm{P}=\%$ gestations with bull-calf product in the seventh AI; $P L C 1_{t-14}=$ pregnant lactating cow after first $\mathrm{AI}$ in the period $\mathrm{t}-14 ; P L C 2_{t-14}=$ pregnant lactating cow after second $\mathrm{AI}$ in the period $\mathrm{t}-14 ; P L C 3_{t-14}=$ pregnant lactating cow after third AI in the period $\mathrm{t}-14 ; P L C 4_{t-14}=$ pregnant lactating cow after fourth $\mathrm{AI}$ the period $\mathrm{t}-14 ; P L C 5_{t-14}=$ pregnant lactating cow after fifth $\mathrm{AI}$ in the period $\mathrm{t}-14 ; P L C 6_{t-14}=$ pregnant lactating cow after sixth $\mathrm{AI}$ in the period $\mathrm{t}-14 ; P L C 7_{t-14}=$ pregnant lactating cow after seventh $\mathrm{AI}$ in the period $\mathrm{t}-14 ; P H 1_{t-14}=$ pregnant heifers after first AI in the period $\mathrm{t}-14 ; P H 2_{t-14}=$ pregnant heifers after second AI in the period $\mathrm{t}-14 ; P H 3_{t-14}=$ pregnant heifers after third AI in the period $\mathrm{t}-14 ; P H 4_{t-14}=$ pregnant heifers after fourth $\mathrm{AI}$ in the period $\mathrm{t}-14 ; P H 5_{t-14}=$ pregnant heifers after fifth AI in the period $\mathrm{t}-14 ; \Pi=\%$ mortality rate in lactating cows; $\mathrm{B}=\%$ pregnancy loss in cows $>90$ days; $\mathrm{A}=\%$ pregnancy loss in heifers $>90$ days; and $\epsilon=\%$ mortality rate in adult animals.

$B C S_{t}=B C_{t}(1-\psi) \Xi \forall \mathrm{t}$

in which $B C S_{t}=$ bull-calf for sale in the period t; $B C_{t}=$ bull-calf in the period t; $\psi=\%$ mortality rate in bull-calf; and $\Xi=\%$ bull-calfs for sale.

$F C_{1}=\gamma L C \forall \mathrm{t}=1$

in which $F C_{1}=$ cow-calf ( $<3$ months) in the period $\mathrm{t}=1 ; \gamma=\%$ gestations with bull-calf/cow-calf product by natural service; and $L C_{1}=$ lactating cow in the period $\mathrm{t}=1$.

$F C_{t}=\left(\left(\left(\left(\left((1-\xi) P L C 1_{t-14}+(1-o) P L C 2_{t-14}+(1-\pi) P L C 3_{t-14}+(1-\Upsilon) P L C 4_{t-14}+(1-\varphi) P L C 5_{t-14}+(1-\chi) P L C 6_{t-14}+(1-\mathrm{P}) P L C 7_{t-14}\right)(1-\Pi)^{11}\right)\right.\right.\right.$ $\left.(1-\epsilon))(1-\mathrm{B}))(1-\epsilon)^{3}\right)+\left(\left(\left((1-\xi) P H 1_{t-14}+(1-o) P H 2_{t-14}+(1-\pi) P H 3_{t-14}+(1-\Upsilon) P H 4_{t-14}+(1-\varphi) P H 5_{t-14}\right)(1-\epsilon)^{14}\right)(1-\mathrm{A})\right) \forall \mathrm{t}>1$

in which $C F_{t}=$ cow-calf - number of calves born after the reproductive program of the farm, taking into account the semen technology used in the period $\mathrm{t}>1 ; 1-\xi=\%$ gestations with cow-calf product in the first AI; $1-o=\%$ gestations with cow-calf product in the second AI; $1-\pi=\%$ gestations with cow-calf product in the third AI; $1-\Upsilon=\%$ gestations with bull-calf product in the fourth AI; $1-\varphi=\%$ gestations with bull-calf product in the fifth AI; $1-\chi=\%$ gestations with bull-calf product in the sixth AI; $1-\mathrm{P}=\%$ gestations with bull-calf product in the seventh AI; $P L C 1_{t-14}=$ pregnant lactating cow after first AI in the period t $-14 ; P L C 2_{t-14}=$ pregnant lactating cow after second AI in the period $\mathrm{t}-14 ; P L C 3_{t-14}=$ pregnant lactating cow after third $\mathrm{AI}$ in the period $\mathrm{t}-14 ; P L C 4_{t-14}=$ pregnant lactating cow after fourth $\mathrm{AI}$ the period $\mathrm{t}-14 ; P L C 5_{t-14}=$ pregnant lactating cow after fifth AI in the period $\mathrm{t}-14 ; P L C 6_{t-14}=$ pregnant lactating cow after sixth AI in the period $\mathrm{t}-14 ; P L C 7_{t-14}=$ pregnant lactating cow after seventh AI in the period $\mathrm{t}-14 ; P H 1_{t+14}=$ pregnant heifers after first $\mathrm{AI}$ in the period $\mathrm{t}-14 ; P H 2_{t-14}=$ pregnant heifers after second $\mathrm{AI}$ in the period t $-14 ; P H 3_{t-14}=$ pregnant heifers after third AI in the period $\mathrm{t}-14 ; P H 4_{t-14}=$ pregnant heifers after fourth AI in the period $\mathrm{t}-14 ; P H 5_{t-14}=$ pregnant heifers after fifth $\mathrm{AI}$ in the period $\mathrm{t}-14 ; \Pi=\%$ mortality rate in lactating cows; $\mathrm{B}=\%$ pregnancy loss in cows $>90$ days; $\mathrm{A}=\%$ pregnancy loss in heifers $>90$ days; and $\epsilon=\%$ mortality rate in adult animals.

$F F=\left(\left(L C 7_{t}-P L C 7_{t}\right)+\left(L C 7_{t} \mathrm{HI}(1-\Pi)\right) \beta+\left(\left(\left(\left(P L C 1_{t-14}+P L C 2_{t-14}+P L C 3_{t-14}+P L C 4_{t-14}+P L C 5_{t-14}+P L C 6_{t-14}+P L C 7_{t-14}\right)(1-\Pi)^{11}\right)(1-\epsilon)\right) \mathrm{B}\right.\right.$ $\left.\left.(1-\epsilon)^{3}\right)\right)+\left(\left(\left(H 5_{t}-P H 5_{t}\right)+\left(\left(H 5_{t-1} \mathrm{X} \Phi(1-\epsilon)\right) \alpha\right)\right)+\left(\left(\left(P H 1_{t-14}+P H 2_{t-14}+P H 3_{t-14}+P H 4_{t-14}^{t-14}+P H 5_{t-14}^{t-14}\right)(1-\epsilon)^{14}\right) A\right)\right) \forall t>1$

in which $F F=$ female fattening in the period $\mathrm{t} ; L C 7_{t}=$ lactating cows available for seventh in the period $\mathrm{t} ; P L C 7_{t}=$ pregnant lactating cow after seventh AI in the period $\mathrm{t} ; P L C 1_{t-14}=$ pregnant lactating cow after first $\mathrm{AI}$ in the period $\mathrm{t}-14 ; P L C 2_{t-14}=$ pregnant lactating cow after second $\mathrm{AI}$ in the period $\mathrm{t}-14 ; P L C 3_{t-14}=$ pregnant lactating cow after third $\mathrm{AI}$ in the period $\mathrm{t}-14 ; P L C 4_{t-14}=$ pregnant lactating cow after fourth $\mathrm{AI}$ in the period t-14; $P L C 5_{t-14}=$ pregnant lactating cow after fifth $\mathrm{AI}$ in the period $\mathrm{t}-14 ; P L C 6_{t-14}=$ pregnant lactating cow after sixth AI in the period $\mathrm{t}-14 ; P L C 7_{t-14}=$ pregnant lactating cow after seventh $\mathrm{AI}$ in the period $\mathrm{t}-14 ; H 5_{t}=$ heifers available for fifth $\mathrm{AI}$ in the period $\mathrm{t} ; P H 5_{t-14}=$ pregnant heifers after fifth AI in the period $\mathrm{t}-14 ; P H 5_{t}=$ pregnant heifers after fifth $\mathrm{AI}$ in the period $\mathrm{t} ; P H 1_{t-14}=$ pregnant heifers after first AI in the period $\mathrm{t}-14 ; P H 2_{t-14}=$ pregnant heifers after second AI in the period $\mathrm{t}-14 ; P H 3_{t-14}=$ pregnant heifers after third AI in the period $\mathrm{t}-14 ; P H 4_{t-14}=$ pregnant heifers after fourth $\mathrm{AI}$ in the period $\mathrm{t}-14 ; P H 5_{t-14}=$ pregnant heifers after fifth $\mathrm{AI}$ in the period $\mathrm{t}-14 ; \mathrm{H}=\%$ oestrus detection rate in cows in the seventh $\mathrm{AI} ; \mathrm{I}=\%$ conception rate in cows in the seventh $\mathrm{AI} ; \Pi=\%$ mortality rate in lactating cows; $\beta=\%$ pregnancy loss in cows $<90$ days; $\mathrm{B}=$ $\%$ pregnancy loss in cows $>90$ days; $\epsilon=\%$ mortality rate in adult animals; $\mathrm{X}=\%$ oestrus detection rate in heifers in the fifth $\mathrm{AI} ; \Phi=\%$ conception rate in heifers in the fifth $\mathrm{AI} ; \mathrm{A}=\%$ pregnancy loss in heifers $>90$ days; and $\alpha=\%$ pregnancy loss in heifers $<90$ days.

Table 5 - Results of Payback, NPV (US\$), and IRR as techniques of economic feasibility analysis for the different scenarios proposed in dairy herd

\begin{tabular}{lccccc}
\hline Scenario & Payback $^{1}$ & NPV $^{2}$ & $\begin{array}{c}\text { Variation of } \\
\text { NPV }(\%)^{3}\end{array}$ & IRR (\%) & $\begin{array}{c}\text { Variation of } \\
\text { IRR }(\%)^{4}\end{array}$ \\
\hline TAIS & 25 & 662891 & 19.92 & 63.52 & 6.86 \\
TAIC & 23 & 741800 & 34.20 & 70.22 & 18.14 \\
AIS & 27 & 520469 & -5.84 & 54.76 & -7.87 \\
AIC & 26 & 557773 & 0.00 & 59.44 & 0.00 \\
\hline
\end{tabular}

NPV - net present value; IRR - internal rate of return per year; TAIS - timed artificial insemination using sex-sorted semen; TAIC - timed artificial insemination using conventional semen; AIS - artificial insemination using sex-sorted semen; AIC artificial insemination using conventional semen.

${ }^{1}$ The Payback is expressed in periods (21 days).

${ }^{2}$ NPV considering period of 25 years and discount rate of $10 \%$ per year.

${ }^{3}$ Variation of NPV (base: AIC).

${ }^{4}$ Variation of IRR (base: AIC). of return values were of US\$ 741800 and $70.22 \%$ per year, respectively. The TAIS scenario had its payback in period 25, the net present value was US\$ 662891, and the internal rate of return was $63.52 \%$ per year. In addition to the results of economic viability, the model allowed the observation of the behaviour of variables, such as the composition of the herd through different periods. It was also possible to infer the effects of different scenarios on the culling dynamics.

Figure 2 describes the herd dynamics over the 25 years of simulation depending on the reproductive strategy employed. The four scenarios started their animal inventory with 140 pregnant heifers. Starting from this value, each 


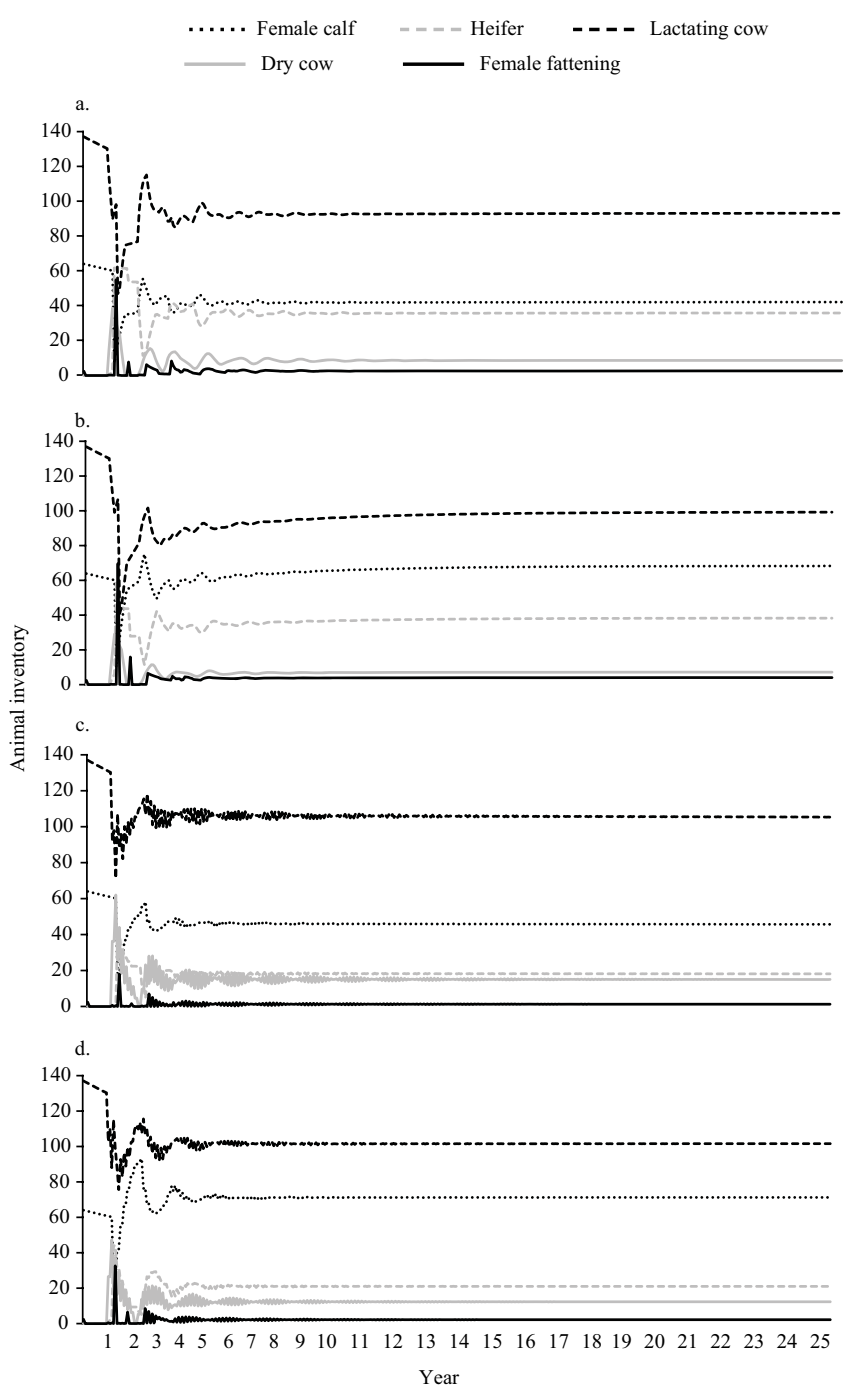

a: artificial insemination using conventional semen after oestrus detection (AIC); b: artificial insemination using sex-sorted semen after oestrus detection (AIS); c: timed artificial insemination using conventional semen (TAIC); d: timed artificial insemination using sex-sorted semen (TAIS).

Figure 2 - Stock of different categories of animals in dairy herd over 25 years according to each scenario.

scenario evolved according to its own parameters. It was possible to observe the effect that each reproductive strategy had on the animal inventory of the farm over 25 years. In the AIC and AIS scenarios (Figures $2 \mathrm{a}$ and $2 \mathrm{~b}$ ), an increase in reproductive failures led to a high rate of animal cull, especially due to cows that remained open. This resulted in an acute decrease in the lactating cow inventory, only compensated by the purchase of pregnant heifers. Besides, for AIC scenario, all pregnant heifers must be retained without the possibility of sale. Moreover, to maintain the animal inventory stable, it was necessary to purchase an average of 10 and 34 pregnant heifers per year in AIC and AIS scenarios, respectively.

Scenarios using TAI showed that the increase in service rate is favourable for stability in the number of animals in the herd. In addition to keeping the number of animals constant, the TAIS scenario (Figure 2d) required less pregnant heifers for replacement compared with TAIC (Figure 2c). In this way, a greater number of pregnant heifers were available for sale in the TAIS scenario. In the scenarios with TAI, the purchase of pregnant heifers was not necessary.

The effect that the pregnancy rate had on the structure and flow of the animal categories over time was remarkable. This effect was particularly negative in the AIC and AIS scenarios. Pregnancy rates lower than $13 \%$ in combination with the cull policy established (after seven inseminations in cows and five in heifers, the open females were culled) resulted in a high animal cull. The mean culling rate for the simulated 25 years was 43.30 and $64.89 \%$ for AIC and AIS, respectively. For the TAI scenarios, these rates were lower, at $21.12 \%$ for TAIC and $36.40 \%$ for TAIS.

The simulation allowed discrimination of the source of incomes depending on the reproductive program in the studied time interval. Thus, for the AIC scenario, $92.75 \%$ of the total revenues in the studied period came from milk sales and the remaining $7.25 \%$ was a result of animal sales. For AIS, the proportions of revenues were $84.12 \%$ for milk and $15.88 \%$ for animals. The TAIC scenario presented values of $89.08 \%$ for milk and $10.92 \%$ for animal sales. In the TAIS scenario, $80.71 \%$ of the revenues were from milk sales and $19.29 \%$ were from animal sales.

The total milk production in the analysed time horizon was $21.3 \times 10^{6}, 21.9 \times 10^{6}, 23.7 \times 10^{6}$, and 22.6 $\times 10^{6} \mathrm{~L}$, respectively, for AIC, AIS, TAIC, and TAIS. The total production cost per litre of milk for AIC, AIS, TAIC, and TAIS was US\$ 0.16 , US\$ 0.19 , US\$ 0.15 , and US\$ 0.18 , respectively.

Using the simulation model, it was possible to calculate the total income from animal sales. Additionally, it was possible to determine the average participation of each animal category in the total income value of the 25 years (Figure 3). There was an effect of reproductive performance on animal sales. On the one hand, AIS, TAIC, and TAIS presented an important offer of pregnant heifers for sale (Figures 3b, 3c, and 3d). On the other hand, AIC scenario is forced to use all of the pregnant heifer production to maintain the number of females, thus preventing their sale (Figure 3a). Therefore, the proceeds from the sale of animals in this scenario is limited to the female fattening and male calf categories.

The relationship between costs per category and the animal inventory flow determines the expenses related to maintaining the herd. These expenses change according to the reproductive strategy employed because of the 
influence that it exerts on the structure of the herd. The scenarios using sex-sorted semen (AIS-TAIS) show slight differences in their distribution of expenses (Figure 4). Specifically, there are increases in the costs for young

a.
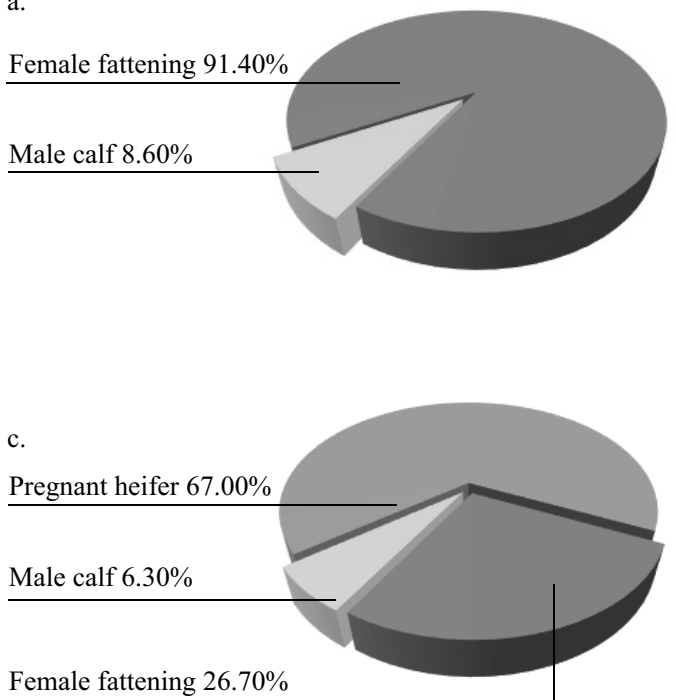

females (under one year old) as a consequence of the increased number of animals in these categories (Figures $4 \mathrm{~b}$ and $4 d$ ). The costs arising from the reproductive strategy are not considered here.

b.
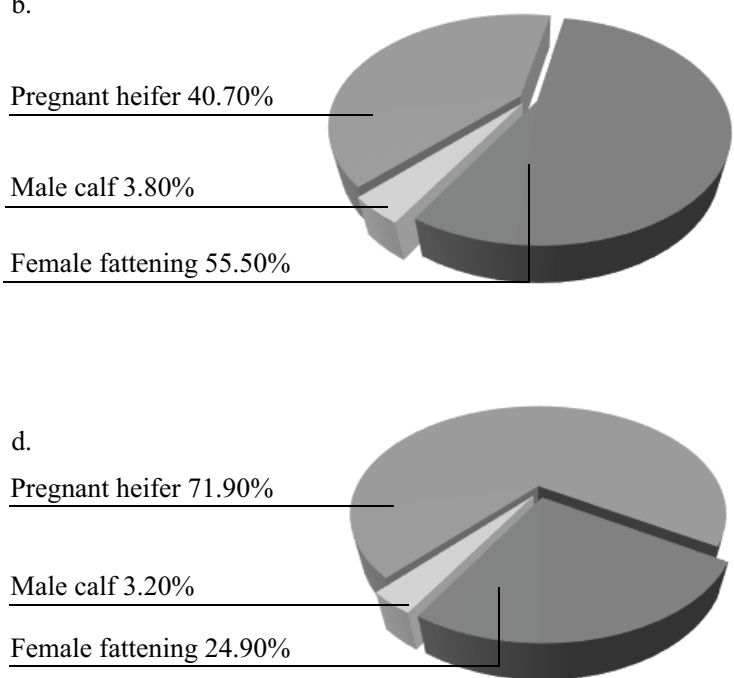

a: artificial insemination using conventional semen after oestrus detection (AIC); b: artificial insemination using sex-sorted semen after oestrus detection (AIS); c: timed artificial insemination using conventional semen (TAIC); d: timed artificial insemination using sex-sorted semen (TAIS).

Figure 3 - Average participation of each of the animal categories of dairy herd in the total income per sale of animals during the total time horizon analysed for each scenario.

a.
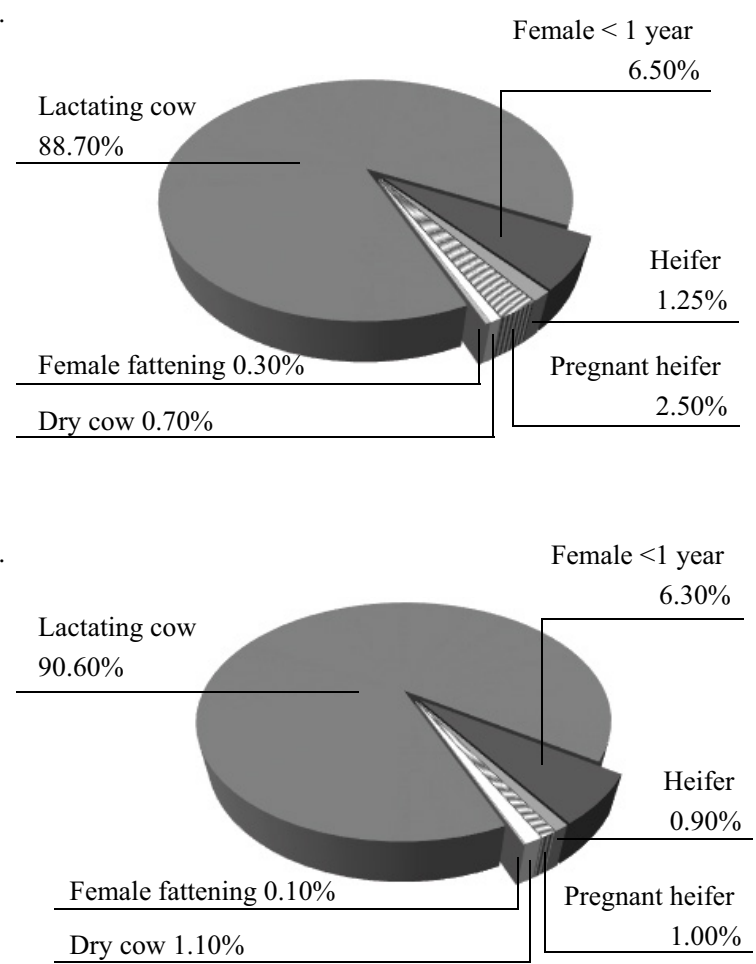

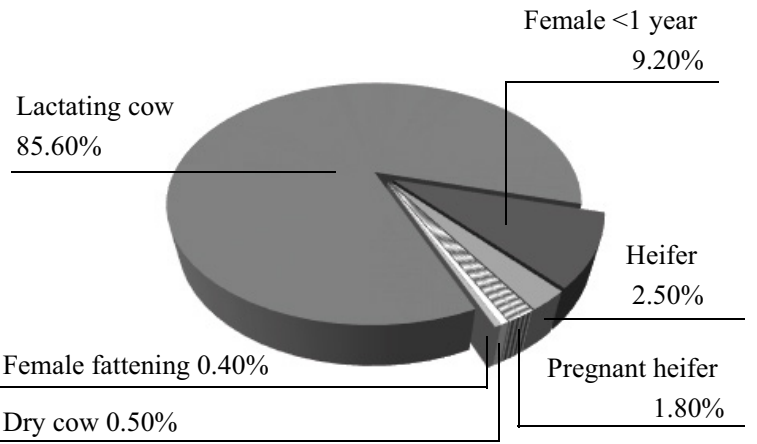

d.

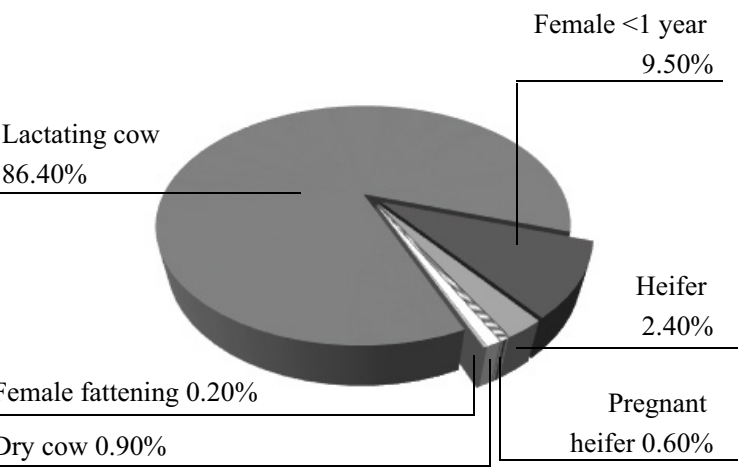

a: artificial insemination using conventional semen after oestrus detection (AIC); b: artificial insemination using sex-sorted semen after oestrus detection (AIS); c: timed artificial insemination using conventional semen (TAIC); d: timed artificial insemination using sex-sorted semen (TAIS).

Figure 4 - Average participation of each of the animal categories of dairy herd in health and nutrition expenses during the total time horizon analyzed for each scenario. 
The scenarios considered vary substantially in their cost. The simulation model allowed the costs of each reproductive management strategy to be linked to the average number of females (cows and heifers) that entered the reproductive program. Thus, the average costs incurred were calculated for each of the reproductive strategies studied. These variations depended on both the cost per animal and the number of females treated. An average of 252 and 331 females were treated annually in the AIC and AIS scenarios, respectively. In contrast, scenarios that included TAI showed an increase in the number of treated females, with 404 and 524 females treated per year in TAIC and TAIS, respectively.

The cost per AI was US\$ 8.89, US\$ 25.19, US\$ 15.27, and US\$ 31.57 for AIC, AIS, TAIC, and TAIS, respectively. Therefore, it is possible to infer that a greater adoption
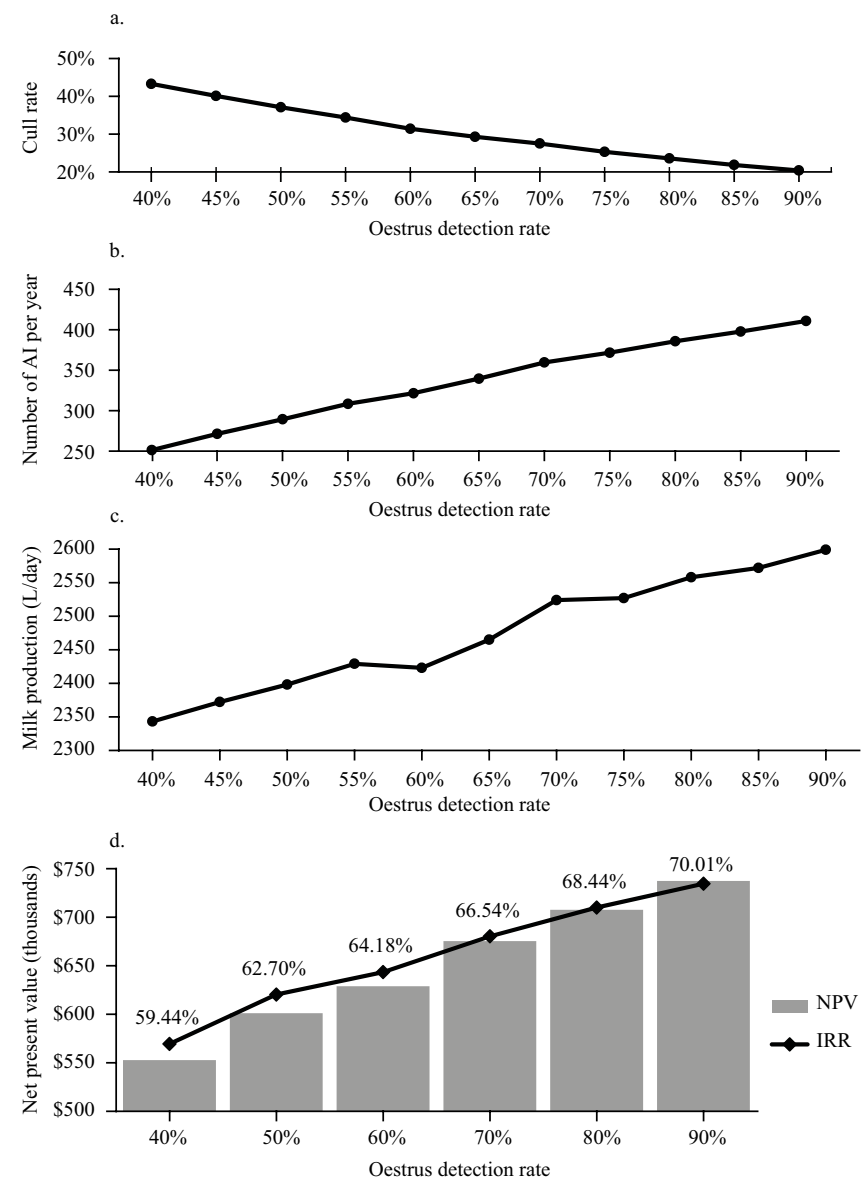

NPV - net present value; IRR - internal rate of return.

a: average cull rate per year; b: average number of artificial insemination (AI) per year; c: average of total milk production of the herd per day; d: net present value and internal rate of return.

Figure 5 - Sensitivity analyses for the artificial insemination using conventional semen after oestrus detection (AIC) scenario to determine the effect of increasing the oestrus detection rate (maintaining the values of all other parameters constant). of technology effectively involves a greater amount of resources. Specifically, the scenarios that included sex-sorted semen presented a significant increase compared with other scenarios. When analysing the average cost of the reproductive program over the 25 years of the simulation, it was possible to determine that the TAIS scenario exceeded the cost of the AIC scenario by 7.42 times.

Finally, the sensitivity analysis for the AIC scenario showed a decrease in the culling rate when the oestrus detection rate increased. The culling rate decreased by $8 \%$ on average for each increase in the oestrus detection rate. When the oestrus detection rate was $40 \%$, the culling rate was $43.3 \%$, and when the oestrus detection rate was $90 \%$, the culling rate dropped to $20.4 \%$ (Figure 5a). Also, for each $5 \%$ increase in the oestrus detection rate, there was an average increase of $5 \%$ in the number of inseminated cows. For example, an average of 252 and 411 females were inseminated per year when the oestrus detection rate was 40.0 and $90.0 \%$, respectively (Figure 5b). Each increase in oestrus detection rate led to a $1 \%$ increase in the daily milk production of the herd. Therefore, when the oestrus detection rate was set at $40.0 \%$, the average total herd milk production per day was $2343 \mathrm{~L}$. When the oestrus detection rate was increased to $90.0 \%$, milk production increased to $2599 \mathrm{~L}$ (Figure 5c). As the oestrus detection rate increased, the internal rate of return and net present value increased by an average of 2 and 3\%, respectively. Thus, when the oestrus detection rate was set at $40.0 \%$, the internal rate of return and the net present value were $59.44 \%$ per year and US\$ 552773; when it was set at $90 \%$, the values were $70.01 \%$ per year and US\$ 737322, respectively (Figure $5 \mathrm{~d}$ ).

\section{Discussion}

Based on a simulation model, the present study compared the use of four different reproductive strategies, using AI or TAI with conventional semen or sex-sorted semen, on the technical and economic performance of a dairy herd. Scenarios that included TAI resulted in a higher net present value compared with AI. The scenario with the best economic results was TAIC. The reproductive and economic performance of the dairy herd are strongly correlated, since parameters such as milk production and animal replenishment are a direct consequence of reproductive outcomes.

This study provided evidence that the low pregnancy rate obtained in the AIS scenario determined poor economic performance due to low milk production, high culling rates, and an increase in replacement costs. These results contrast with the study performed by Hutchinson et al. (2013), who 
evaluated the economic performance of AI with fresh and frozen sex-sorted and conventional semen in heifers and lactating cows in a dairy herd in Ireland. Their economic results showed that the use of frozen sex-sorted semen was superior to the use of conventional semen. These divergent results can be probably attributed to differences between the simulation models, such as the number of inseminations and conception rates for frozen sex-sorted semen in heifers considered by the Irish study and the present study (53 vs. $39 \%$, respectively). Additionally, we also considered the use of sex-sorted semen in adult cows with an even lower conception rate $(23 \%)$.

The current study was consistent in showing the close relationship between reproductive efficiency and animal culling. In this context, De Vries et al. (2010) estimated that the risk of culling a pregnant cow versus an empty cow was approximately $25 \%$. This interaction between low-reproductive performance and high culling rates results in the early sale of females and greater demands for replacement heifers. These are expensive events in a dairy herd, considering that the value of a cull cow is less than the value of a replacement heifer (Giordano et al., 2012; Galvão et al., 2013; Cabrera, 2014). When the culling rates $(\mathrm{AIC}=43.30 \%$, AIS $=64.89 \%$, TAIC $=21.22 \%$, TAIS $=$ $36.40 \%$ ) and the economic performance of each scenario are analysed, it can be seen that the economic performance decreases if the culling rate increases.

This result is in agreement with the study of Bascom and Young (1998), who suggested that an optimal discard rate in terms of profitability should be less than $30 \%$. Likewise, Dekkers (1991) argued that a decrease in involuntary culling results in an increase in profitability per cow, and this increase is mainly due to the reduction of replacement costs.

As described by LeBlanc (2007), whether successful or not, the reproductive strategy modifies the dynamics of the herd. It does so by changing culling rates and repositioning animals, as well as by generating losses or benefits over time, which in turn may be higher than the costs of implementing the reproductive strategy. Each of the scenarios in the present study was evaluated using the net present value, payback, and internal rate of return, thus allowing an objective comparison of cash flows. Under the simulated conditions, the model indicated that scenarios that included TAI showed better economic performance, although they required greater costs, compared with strategies for inseminating cows after oestrus detection, regardless of the type of semen. These findings validate the results of the study by Giordano et al. (2011), who simulated three reproductive programs in dairy cows - two based on TAI and one based on oestrus detection. The TAI programs presented better economic performance than the oestrus detection program. In the comparison of the economic performance of AI and TAI, the present study differs from the results published by Galvão et al. (2013). They compared the use of AI and TAI taking into account different levels of accuracy for each of the techniques. The authors concluded that even with higher pregnancy rate for programs that included TAI, the profitability was lower compared with AI. Thus, they suggested that a combination of the two techniques would be more profitable.

Simulation is an important tool for assisting in decision-making processes. It is particularly applicable in complex systems with long periods in which multiple variables interact, as is the case in most livestock systems. Simulation gives the manager the opportunity of linking variations in reproductive performance to production and profitability, and it also allows him to change parameters and evaluate the consequences. Use of simulation is, therefore, a very valuable tool and can provide a competitive advantage for the manager (Beukes et al., 2010). Compared with traditional experiments that would require a greater mobilisation of resources and time, simulation provides the opportunity to evaluate several scenarios at a relatively low cost (Hutchinson et al., 2013). Some of the information used in this model, specially relating to reproductive parameters, was taken from studies performed in the United States. Therefore, it is important to recognise the relative limitations of the results obtained from the proposed model with respect to the situation of Brazilian dairy livestock, since the technical parameters refer to a large extent to other localities. However, the main objective of this study was to propose a mathematical model representing the cause-effect relationships between the different parameters and variables. In addition, once realistic parameters have been obtained, whether from scientific experiments or specifically from a production farm, they can be easily imputed in the model to generate locally appropriate results. It is important to remember that the model allows the values of the productive, reproductive, and economic parameters to be easily adjusted according to the own situation of the user. The parameters used in the simulated scenarios allow the validation of the biological concordance with the mathematical interactions simulated in the model.

It will be necessary to carry out future experiments and surveys considering Brazilian conditions so that these values can be verified. This applicability is particularly important, because the economic benefits of reproductive strategies are very dependent on the chosen parameters. As 
a result, the use of reproductive strategies with different parameters may affect the results.

\section{Conclusions}

The simulation of the technical and economic effects of different strategies of reproductive management in dairy herds clearly demonstrated the economic and technical benefits of using timed artificial insemination in dairy herds. These benefits are greater when timed artificial insemination is used with conventional semen, despite the large investment in technology that is required. Using this mathematical model, future studies could be conducted if the assessment of technical and economic viability of new scenarios is required.

\section{References}

Bascom, S. S. and Young, A. J. 1998. A summary of the reasons why farmers cull cows. Journal of Dairy Science 81:2299-2305. https://doi.org/10.3168/jds.S0022-0302(98)75810-2

Beukes, P. C.; Burke, C. R.; Levy, G. and Tiddy, R. M. 2010. Using a whole farm model to determine the impacts of mating management on the profitability of pasture-based dairy farms. Animal Reproduction Science 121:46-54. https://doi.org/10.1016/j. anireprosci.2010.04.191

Britt, J. H. 1985. Enhanced reproduction and its economic implications. Journal of Dairy Science 68:1585-1592. https://doi. org/10.3168/jds.S0022-0302(85)80997-8

Bó, G. A.; Baruselli, P. S. and Mapletoft, R. J. 2013. Synchronization techniques to increase the utilization of artificial insemination in beef and dairy cattle. Animal Reproduction 10:137-142.

Cabrera, V. E. 2014. Economics of fertility in high-yielding dairy cows on confined TMR systems. Animal 8:211-221. https://doi.org/10.1017/S1751731114000512

Chebel, R. C.; Guagnini, F. S.; Santos, J. E. P.; Fetrow, J. P. and Lima, J. R. 2010. Sex-sorted semen for dairy heifers: effects on reproductive and lactational performances. Journal of Dairy Science 93:2496-2507. https://doi.org/10.3168/jds.2009-2858

Congleton, W. R. and Everett, R. W. 1980. Application of the incomplete gamma function to predict cumulative milk production. Journal of Dairy Science 63:109-119. https://doi.org/10.3168/jds. S0022-0302(80)82895-5

De Vries, A. 2006. Economic value of pregnancy in dairy cattle. Journal of Dairy Science 89:3876-3885. https://doi.org/10.3168/ jds.S0022-0302(06)72430-4

De Vries, A.; Olson, J. D. and Pinedo, P. J. 2010. Reproductive risk factors for culling and productive life in large dairy herds in the eastern United States between 2001 and 2006. Journal of Dairy Science 93:613-623. https://doi.org/10.3168/jds.2009-2573

DeJarnette, J. M.; Nebel, R. L.; Marshall, C. E.; Moreno, J. F.; McCleary, C. R. and Lenz, R. W. 2008. Effect of sex-sorted sperm dosage on conception rates in Holstein heifers and lactating cows. Journal of Dairy Science 91:1778-1785. https://doi.org/10.3168/ jds.2007-0964

Dekkers, J. C. M. 1991. Estimation of economic values for dairy cattle breeding goals: bias due to sub-optimal management policies. Livestock Production Science 29:131-149. https://doi. org/10.1016/0301-6226(91)90062-U
Galvão, K. N.; Federico, P.; De Vries, A. and Schuenemann, G. M. 2013. Economic comparison of reproductive programs for dairy herds using estrus detection, timed artificial insemination, or a combination. Journal of Dairy Science 96:2681-2693. https://doi.org/10.3168/jds.2012-5982

Giordano, J. O.; Fricke, P. M.; Wiltbank, M. C. and Cabrera, V. E. 2011. An economic decision-making support system for selection of reproductive management programs on dairy farms. Journal of Dairy Science 94:6216-6232. https://doi.org/10.3168/ jds.2011-4376

Giordano, J. O.; Kalantari, A. S.; Fricke, P. M.; Wiltbank, M. C. and Cabrera, V. E. 2012. A daily herd Markov-chain model to study the reproductive and economic impact of reproductive programs combining timed artificial insemination and estrus detection. Journal of Dairy Science 95:5442-5460. https://doi.org/10.3168/ jds.2011-4972

Hutchinson, I. A.; Shalloo, L. and Butler, S. T. 2013. Expanding the dairy herd in pasture-based systems: The role for sexed semen use in virgin heifers and lactaing cows. Journal of Dairy Science 96:6742-6752. https://doi.org/10.3168/jds.2012-6476

Kuhn, M. T.; Hutchison, J. L. and Wiggans, G. R. 2006 Characterization of Holstein heifer fertility in the United States. Journal of Dairy Science 89:4907-4920. https://doi.org/10.3168/ jds.S0022-0302(06)72541-3

LeBlanc, S. 2007. Economics of improving reproductive performance in dairy herds. p.201-214. In: Proceedings of the 25th Western Canadian Dairy Seminar (WCDS). Red Deer.

Lovatto, P. A. and Sauvant, D. 2001. Modelagem aplicada aos processos digestivos e metabólicos do suíno. Ciência Rural 31:663-670. https://doi.org/10.1590/S0103-84782001000400017

Meadows, C.; Rajala-Schultz, P. J. and Frazer, G. S. 2005. A spreadsheet-based model demonstrating the nonuniform economic effects of varying reproductive performance in Ohio dairy herds. Journal of Dairy Science 88:1244-1254. https://doi.org/10.3168/ jds.S0022-0302(05)72791-0

Norman, H. D.; Hutchison, J. L. and Miller, R. H. 2010. Use of sexed semen and its effect on conception rate, calf sex, dystocia, and stillbirth of Holsteins in the United States. Journal of Dairy Science 93:3880-3890. https://doi.org/10.3168/jds.2009-2781

Overton, M. 2005. Cost comparison of natural service sires and artificial insemination for dairy cattle reproductive management. Theriogenology 64:589-602. https://doi.org/10.1016/j.theriogenology.2005.05.015

Pereira, M. H.; Rodrigues, A. D.; Martins, T.; Oliveira, W. V.; Silveira, P. S.; Wiltbank, M. C. and Vasconcelos, J. L. 2013. Timed artificial insemination programs during the summer in lactating dairy cows: Comparison of the 5-d Cosynch protocol with an estrogen/ progesterone-based protocol. Journal of Dairy Science 96:69046914. https://doi.org/10.3168/jds.2012-6260

Pinedo, P.; De Vries, A. and Webb, D. 2010. Dynamics of culling risk with disposal codes reported by Dairy Herd Improvement dairy herds. Journal of Dairy Science 93:2250-2261. https://doi. org/10.3168/jds.2009-2572

Seidel, G. E. and Schenk, J. L. 2008. Pregnancy rates in cattle with cryopreserved sexed sperm: effects of sperm numbers per inseminate and site of sperm deposition. Animal Reproduction Science 105:129-138. https://doi.org/10.1016/j.anireprosci.2007.11.015

Silva Del Río, N.; Stewart, S.; Rapnicki, P.; Chang, Y. M. and Fricke, P. M. 2007. An observational analysis of twin births, calf sex ratio, and calf mortality in Holstein dairy cattle. Journal of Dairy Science 90:1255-1264. https://doi.org/10.3168/jds.S00220302(07)71614-4

Wiltbank, M.; Lopez, H.; Sartori, R.; Sangsritavong, S. and Gumen, A. 2006. Changes in reproductive physiology of lactating dairy cows due to elevated steroid metabolism. Theriogenology 65:17-29. https://doi.org/10.1016/j.theriogenology.2005.10.003 